\title{
Digital Scholarship: Identity, Interdisciplinarity, and Openness
}

\author{
Eileen Scanlon* \\ Institute of Educational Technoogy, The Open University, Milton Keynes, United Kingdom
}

This paper considers the impact of changes in the landscape of scholarly communication on the activities of academics. These changes are considered through the lens of the practices examined by educational technology academics at the Open University who have conducted a number of related research projects under the theme of digital scholarship. This paper reviews the changes to the definition of scholarship and interviews conducted on academic practices conducted as Phase 1 of these activities [see also Scanlon (2013)]. It then comments on the findings of Phase 2 of the project which investigated the use of social media and the usefulness and visualization of such activities. The findings are considered in the light of trends toward working practices involving interdisciplinarity and openness.

\section{OPEN ACCESS}

Edited by:

Tom Crick,

Cardiff Metropolitan University, United Kingdom

Reviewed by: Nancy Longnecker, University of Otago,

New Zealand

John Roger Hartley, University of Leeds,

United Kingdom

${ }^{*}$ Correspondence:

Eileen Scanlon

eileen.scanlon@open.ac.uk

Specialty section:

This article was submitted

to Digital Scholarship,

a section of the journal

Frontiers in Digital Humanities

Received: 18 August 2017

Accepted: 15 February 2018

Published: 11 April 2018

Citation:

Scanlon E (2018) Digital Scholarship: Identity, Interdisciplinarity, and Openness.

Front. Digit. Humanit. 5:3. doi: 10.3389/fdigh.2018.00003
Keywords: digital scholarship, academic practice, interdiscipinarity, educational technology, openness

\section{INTRODUCTION}

There have been considerable changes in the landscape of scholarly communication the past ten years which have implications for the activities of academics. In this paper, the practices adopted by educational technology academics at the Open University UK (OUUK) are used to consider the impact of these changes. A number of research related research projects under the theme of digital scholarship have been conducted there. For example, the Digital Scholarship project (DISCO) conducted by a team at the Open University from 2009 to 2013 was developed in order to understand the changes in communication and publication practices of academics in higher education due to the impact of the information age [see, e.g., Castells (1996)]. The information age has resulted in a changed landscape which offers researchers new ways of working and also offers new kinds of academic output for educators to incorporate in their teaching. Essentially, the project was an exploration of current academic practices in digital scholarship. This work was inspired by recognition of the impact of the information age on communication both in the sciences and humanities. This impact is becoming quite profound. It affects the way that academics do their work (for example, by access to new tools), the way they work in distributed teams (for example, by access to means of communication which are now available), the way that they communicate their findings (for example, by contributing their papers to open repositories, or discussions to wikis) and the way that they communicate with the public (for example, by writing blogs).

At the starting point of the project, we realized it was important to resist too simple a definition of digital scholarship. Weller (2011) describes a digital scholar as "someone who employs digital, networked and open approaches to demonstrate specialism in a field." He explains that the scholar "need not be a recognized academic or anyone that posts online" (Weller, 2011, p. 4). The particular affordances that make up the changing digital landscape we were exploring have been described by a number of commentators [see, e.g., Pearce et al. (2010), Borgman (2009)].

Veletsianos and Kimmons (2012) describe it as networked participatory scholarship stressing the importance of the participatory media. This view is shared by Katz (2010) who points to the "rapid 
and low-cost connection with others; tools that promote our capacity for multi-tasking, multi-processing, and otherwise dividing our attention; the interconnected and accessible complex of digital instruments and visualization techniques that make it possible for us to work at nano-or cosmic scale; and access to an abundance of easily discovered recorded knowledge" (Katz, 2010, p. 48).

As part of the Open University research project we have explored various definitions of the concept. Even at its simplest the definition that digital scholarship is using digital technologies to support scholarship is helpful. We were able to produce the further elaboration that digital scholarship can mean building artifacts or making tools to build artifacts, using digital archives to generate intellectual products, creating digital tools to study artifacts or creating authoring tools that make use of intellectual products either in traditional or digital forms (Farrow and Coughlan, 2011). A further elaboration was produced by Goodfellow (2013) who distinguishes between "the digital enabling of access to scholarship" and digital scholarship "the relatively recent intervention by cross-disciplinary groups of individual scholars, particularly from education and the humanities, who have begun to use technology to disseminate their work outside the academic publishing system. These scholars have begun to promote the idea that everyday practices of mass open online interaction enabling large-scale exchanges of user-generated content (YouTube, Flickr, Wikipedia) peer-to-peer communication (email, blogging, Twitter) and online social and professional networking (Facebook, LinkedIn) impact on personal and professional practice for scholars" (Goodfellow, 2013, p. 75).

The priorities of scholars whether conventional or digital are still similar. They research, debate and communicate. However, with the new affordances of digital technologies, the way scholars negotiate and navigate information and communicate is changing, and that is mediated by technology. There is a consequential shift in the demands made of scholars in terms of the complex set of technological skills required for them to flourish in this different landscape. The affordances of the new technologies also offer new ways of communication which allow different ways to form communities of scholars. Some argue that there is a need for academic culture to recognize these new types of digital activities of scholars in ways that allow for career progression and promotion. Some tools can be used by digital scholars to establish and explore their academic identity. Some have argued that it is easier to conduct interdisciplinary research in this way [see, e.g., Scanlon and Taylor (2016)]. Some would argue that these new ways of working and interdisciplinary practices are the most important features of digital scholarship (Scanlon, 2011). Others focus on the consequences of the new models for publication and dissemination of research [see, e.g., Holliman (2010); Weller (2011)].

One of the first activities undertaken in the Open University DISCO was a consideration of Boyer's $(1990,1994)$ functions of scholarship and how they could be impacted by technologies. This resulted in a revised framework for functions of scholarship. Two examples which are explored further here are impact on the scholarship of discovery and the scholarship of teaching. A number of our publications cover this work [Weller (2011), Pearce et al. (2010) and Scanlon (2013)]. Work relating to the scholarship of discovery, involving the discovery of new knowledge, results in the creation of new data. There have been changes in academic practice related to data which now is stored and shared digitally. The move to digital manuscript preparation has opened up new ways of collaborating on texts and new ways of publishing which have implications for the scholarship of integration. In terms of the scholarship of application there are interesting consequences of the move toward digital scholarship. In addition to conventional approaches, scholars can make use of networked communities to develop new forms of public engagement with research [see, e.g., Colebeck and Michael (2006); Grand et al. (2015)]. An example of the consequences of this can be seen in relation to debates about controversial issues such as climate change. Holliman (2011) describes ways in which the use of digital tools played a part in the progress and outcomes of online communication. Holliman (2010) also reflects on his own experience in moving from analog to digital scholarship in the field of science communication and the ways in which all stages of the research process were influenced.

This influences data collection and analysis, and the ways that research questions are conceptualized. But researchers are also: registering for automated and personalized updates from possible funders; searching for, and communicating online with, international collaborators; blogging and social networking about research processes; using networked computers to source literature, and analyze and archive data; in some instances, checking for existing patents and contributing to new applications; in others, responding to requests made under Freedom of Information legislation; and producing a wider range of outputs from research projects, including podcasts and web video. (Holliman, 2010, p. 4)

Holliman also describes how the new possibilities for publication are shifting the concept of "publication."

Final reports are still required, but they can now be published online in the form of 'gray literature', perhaps in open repositories. Peer reviewed publications, which can be published via pre-print servers, still hold currency, but are now increasingly published in open access journals and via open review. Moreover, researchers are now expected to upload papers and grants for review via digital interfaces for academic journals and research funders, respectively. The fact that papers and grant applications can be submitted via web portals means that additional information, such as raw data in the case of research papers, and project reports in the case of grant applications, can also be submitted. (Holliman, 2010, p. 4)

A further implication of the increased use of digital technology which has influenced scholarship is that learning and teaching resources are created digitally. This changes the ease with which the resources can be shared, and therefore, the possibility of accessing resources produced by others is increased, and vastly 
increased if approaches such as those advocated by open educational resources (OER) movement are taken [see, e.g., Lane and McAndrew (2010)]. So, digital scholarship is also changing the scholarship of teaching and learning.

At the OUUK in the DISCO we researched existing practice both within and outside the University and investigated the changing nature of scholarly practice, in particular the impact of new technologies on scholarly practice and academic identity. The purpose was to engage academics in wider discussion of open digital methods, and the role of the scholar in the digital world. In addition, there were discussions in the institution about the appropriate structure for rewards for activities that increase the impact of research and scholarship. This work was progressed in two phases.

In Phase 1, two sets of studies were carried out to investigate how new technologies were used. In Phase 2, two further sets of studies were carried out to investigate the use of social media and the usefulness and visualization of such activities, a focus group study and an ethnographic study. The Phase 1 studies consisted of an interview study between 2009 and 2010 and an observational study conducted between 2010 and 2011. In the interview study, 22 interviews of academics of different levels of seniority were conducted [see Scanlon (2013) and Pearce et al. (2010) for more detail on the conduct and outcomes of this phase of the project]. These semi-structured interviews were conducted either face-toface, or by telephone or Skype. The questions investigated the use of new technologies, the influence of new technology on scholarly practices and how social networking interactions were influencing interaction with others. The main focus in constructing the interview sample was on educational technologists, technologists, and scientists, with two other subject specialists with some experience of educational technology included. Job descriptions of the interviewees included "educational technologist" but also "learning technologist" and "e-learning specialist." The sample included a range of job titles (from research fellow to professor) and different activities with the most of them were involved in both teaching and research. In the interviews we explored how the changes in the professional practices of academics were influenced by the introduction of new technologies.

In Phase 2, two other lines of inquiry of the work were developed. These included a survey and qualitative case study of a research group and a focus group to explore in depth some of the perceptions of Twitter among university scholars (both users and non-users). We wanted to explore how various visualizations of scholarly activity could provide reflection and learning. A tool for measuring the "digital footprint" of the academic (i.e., the traces left behind in digital environments) both to prompt personal reflection on the use of digital resources and to capture information on the use of the digital resources was developed. The second objective was further to understand how and why certain resources were being used by means of a survey. Fransman (2013) and Farrow and Coughlan (2011) describe the second phase of the study and the outcomes of this phase of the work in more detail. The survey was administered to Open University academics in Science and Arts. At that time they found that $26 \%$ of academics had Twitter accounts. An interactive visualization tool was developed which contained a chart of Twitter use as well as the use of other platforms, the number of Tweets over time shown graphically, and, for each individual user, pie charts which showed the most used phrases and the most mentioned user. The tool also included list of all Tweets which were ordered in terms of the number of retweets.

The conclusion drawn from the study was that a strong "digital footprint" increases the influence academics have in academic networks. They found that the connection and mediation of people was aided by certain individuals who acted as hubs, using Twitter, but going beyond to other digital resources. These individuals tended to be users of a wide range of digital resources including Twitter but going beyond it. Their influence in the network is shown in the visualization by the number of their posts, how often they were mentioned or followed by others, and how often they were retweeted.

One of the aims of this work was to make the usefulness and value of Twitter and other social media more apparent to current non-users through these and other visualizations. However the detailed accounts of Twitter use provided interesting insights. The focus group discussions gave a mixed view of the role of social media and the draft visualizations. Fransman (2013) summarizes these as follows: "Twitter was portrayed as an individual as opposed to a social practice" (Fransman, 2013, p. 9).

The ethnographic case study was conducted over a 3-month period and involved observations of the team meetings of a Humanities-based research project and included interviews with key participants. The project involved places in the Ancient World and the use of linked open data introduced into online resources. Findings about Twitter use were quite complex. The research question was posed as "how do digital resources such as Twitter help to construct and challenge the boundaries of academic communities?" (Fransman, 2013, p. 35) Fransman found that:

Twitter use was found to be distinctly social with non-Twitter-using team members often having a direct impact on the content of tweets (translated from conversations or emails by Twitter-using colleagues). Materially, Twitter use could not be segregated from other digital and non-digital literacy practices since ideas and information crossed multiple channels of communication over the course of their development. And the use of Twitter was not consistent even within an individual user but rather evolved over time as users experimented, learned from their peers and used Twitter on new devices against an evolving backdrop of social etiquette in the broader Twittosphere. (Fransman, 2013, p. 35)

There were other insights from this work including perceptions related to institutional and disciplinary reward structures and the value of connecting with (or for) remote workers. The conventional currency of a success in these areas includes grant awards, publications. So far tweeting and being retweeted is not high on that list of performance indicators.

The work begun in this project chimes with some of the writings of key commentators in this area. For example, Borgman (2009) discusses how digitization of data in the sciences is 
leading to changes in academic practice and emphasizes that collaborative cross-disciplinary partnerships, especially with computer scientists, would be beneficial. "We are only beginning to understand what constitute data in the humanities, let alone how data differ from scholar to scholar and from author to reader" (Borgman, 2009, para 29, page 10). Schmiede (2009) makes an assessment of the current information infrastructure for promoting academic scholarship and agrees with Borgman's assessment of the existence of an infrastructure of (rather than for) scholarly information.

Jenkins et al. (2009), an influential scholar on the new media, points out the need to understand the new media landscape in which scholars are working by "looking at the interrelationship between all the communication technologies, the cultural communities that grow up around them, and the activities they support" (Jenkins et al., 2009, p. 7). The next section is a reflection on these new communities and skills.

\section{INTERDISCIPLINARITY AND OPENNESS IN DIGITAL SCHOLARSHIP}

Among these newly required skills, such as the use of social media, are the skills of interdisciplinary working. This is due to the formation of communities enabled by technology such as the extended collaborative groups working around digital archives. These archives can enable other stakeholders in research to engage in dialog as well as increase the dialog between researchers in different disciplines. The potential here is that new solutions to problems can be created as well as new ways of thinking about such solutions. Klein $(1990,2010)$ describes the way that, in digital humanities, digital practices such as these can change the nature of traditional disciplines, although she rejects simple distinctions between disciplinarity and interdisciplinarity. Barry et al. (2008) also discuss the complexity of these distinctions. Communication technologies can allow the creation of communities over geographical distance. Similar types of tools mean that research results can be made available to a much bigger audience.

Working in an open fashion by scholars is also enabled by the use of digital tools. In 2014, Weller (2014) reviewed his definition of open scholarship. He reminds us that digital scholarship has three elements, digital, networked and open and is eloquent on the importance of open in these new scholarship practices. In particular in relation to teaching, access to OER is one of the motivations for scholars toward changing their practice. In some cases access to OER and other such teaching practices are the impetus for a move toward becoming a digital scholar (Pearce et al., 2010). Wilinsky and Alperin (2011) provide a powerful case for the primacy of academic ethics as the principle by which scholarly publications are disseminated, arguing for open access and, among other points, citing the risks of limiting researchers' access to digital scholarly resources. More recently, however, commentators [see, e.g., Singh (2016)] have questioned both the strategic advantage and the risks of openness on reputations. For example, the extent to which having an active social media profile was an expectation and pressure for newer academics and Ph.D. students, and how this created various risks which could adversely affect particular populations. Collins et al. (2016) have made a useful contribution to the knowledge on academic practices by their study of scientists' use of workplace social media.

Strober (2011) provides interesting insights into what can make interdisciplinary conversations work drawing on definitional work of Moran (2010) and Turner (2000) on the nature of interdisciplinarity. These insights were drawn from interviews with 40 faculty members participating in interdisciplinary seminars. She emphasizes that the traditional discourse of academic conversations which she describes as "the doubting game," need to be replaced by "the believing game" and what Yankelovich (1999) describes as "listening with empathy." This has particular importance for the digital networks which may be created round artifacts.

Goodfellow (2013) develops an interesting way of contrasting two major digital scholars to compare their "disciplinary footprint." He measured this in a number of ways by searching for each name on the internet combined with the words "digital scholar" p. 75. An example of the use he makes of such measures is as follows. The search for each name combined with "digital scholar" shows 650 hits for Weller between 2006 and 2011 compared with 280 hits for Borgman for the same period. However, in terms of citations on Google Scholar, Borgman had 364 citations of her most recent book (Borgman, 2010) as compared to Weller's 51 citations for a 2011 book. Borgman and Weller have different foci in the arguments they make, and in the nature of their arguments. Borgman takes the stance of writing for an audience that is professionally engaged in scholarly communication but needs to understand the use of institutional shaping relation between the technology and social change. This is contrasted with Weller's informal but didactic approach taking " a more cultural account of control over traditional scholarship and the likelihood of this being disrupted by digital practices that have already transformed other cultural industries." He summarizes his impressions as follows "Borgman is trying to make digital scholarship more scholarly while Weller is trying to make it more digital" (Goodfellow, 2013, p. 75).

\section{BEYOND THE DISCO}

A further development of this research exploring the practices of digital scholarship was the OU's bid to the Research Councils UK to become one of eight "Public Engagement with Research" Catalyst universities. Like the DISCO project the focus was on scholarly practices, exploring how they are changing. A further development in their proposal was an initiative to discover what measures could be introduced to catalyze change within the institution to further develop the practices of engaged research. This project (Holliman et al., 2015) adopted an action research approach, working collaboratively with researchers at all levels across the institution to identify and implement strategies that work for them and for the stakeholders, user communities and members of the public that engage with their research. The interventions introduced with the aim of improving researcher engagement, included the promulgation of a definition of engaged research. Revised promotion procedures were developed and approved for the advancement of academic staff in the institution that give credit for engaged research. This involved the introduction of knowledge exchange profiles. 


\section{CONCLUSION}

All activities are changed by the use of technology. Scholarship in the digital university is but one example. As demonstrated here the changes in scholarship due to the digital turn require a reframing of Boyer's categories, and require a revolution in the practices of academics. The shift from analog to digital scholarship affects all stages of the research process and the teaching methods within universities. This paper has synthesized work from three phases of work on digital scholarship and public engagement over 6 years, reviewing the changes to the definition of scholarship and practices described in the interviews conducted on academic as phase 1 of these activities [see also Scanlon (2013)]. This work has involved surveying and interviewing academics, conducting focus groups with them, investigating the use of visualization tools and conducting ethnography of the use of social media in a research project. This research has implications for the skills for academics to thrive and, therefore, for the functions of a university.

An underlying theme of this work is that the key dimensions of digital scholarship require open, participatory and interdisciplinary methods. This paper has explored the concept of digital scholarship and reported on some work investigating changes to academic practice resulting from the access to digital resources and scholarship on the Internet. In our current work, we are exploring the rise of citizen science in which some academics

\section{REFERENCES}

Barry, A., Born, G., and Weskalnys, G. (2008). Logics of interdisciplinarity. Economy and Society 37: 20-39. doi:10.1080/03085140701760841

Borgman, C. (2009). The digital future is now: a call to action for the humanities. Digital Humanities Quarterly 3.

Borgman, C. (2010). Scholarship in the Digital Age: Information, Infrastructure and the Internet. Cambridge, MA: MIT Press.

Boyer, E. (1990). Scholarship Reconsidered: Priorities of the Professoriate. Stanford: Carnegie Foundation for the Advancement of Teaching, Jossey Bass.

Boyer, E. (1994). A community of scholars. In Keynote Address at Emory College, April 14, In Selected Speeches 1979-1995 ERIC ED413293. Atlanta.

Castells, M. (1996). The Information Age: Economy, Society and Culture, vol 1 the Rise of the Networked Society. Oxford: Blackwell.

Colebeck, C., and Michael, P. (2006). The public scholarship: reintegrating Boyer's four domains. New Directions for Institutional Research 129: 7-19. doi:10.1002/ ir.168

Collins, K., Shiffman, D., and Rock, J. (2016). How are scientists using social media in the workplace? PLoS ONE 11:e016280. doi:10.1371/journal.pone.0162680

Farrow, R., and Coughlan, T. (2011). Reflecting on digital scholarship through activity visualisation. In Plenary Talk at the 2nd Conference on Visual Learning, Budapest University of Technology and Economics. Budapest.

Fransman, J. (2013). Chapter 2 researching academic literacy practices around Twitter: performative methods and their onto-ethical implications. In Literacy in the Digital University: Critical Perspectives on Learning, Scholarship and Technology, Edited by R. Goodfellow and M.R. Lea. Abingdon: SRHE, Routledge.

Goodfellow, R. (2013). Chapter 5 the literacies of digital scholarship'- truth and use values. In Literacy in the Digital University: Critical Perspectives on Learning, Scholarship and Technology, Edited by R. Goodfellow and M.R. Lea, 75. Abingdon: SRHE, Routledge.

Grand, A., Davies, G., Holliman, R., and Adams, A. (2015). Mapping public engagement with research in a UK University. PLoS ONE 10:e0121874. doi:10.1371/ journal.pone. 0121874

Holliman, R. (2010). From analogue to digital scholarship: implications for science communication researchers. Journal of Science Communication 9: C05. have engaged the public directly in their research endeavors (Scanlon et al., 2016).

\section{ETHICS STATEMENT}

The work described in this paper was conducted in accordance with the institution's Human Research Ethics Committee.

\section{AUTHOR CONTRIBUTIONS}

The author confirms being the sole contributor of this work and approved it for publication.

\section{ACKNOWLEDGMENTS}

The author's thanks are due to colleagues involved in the several phases of the work at the OU on digital scholarship, Martin Weller, Katerina Avramides, Nick Pearce, Tim Coughlan, Robert Farrow, Jude Fransman, and Richard Holliman. The author also wishes to thank those who participated in interviews, allowed to track their practices, and completed questionnaires.

\section{FUNDING}

This article reports on work funded by an Open University Strategic project.

Holliman, R. (2011). Advocacy in the tail: exploring the implications of 'climategate' for science journalism and public debate in the digital age. Journalism Theory Practice and Criticism 12: 832-46. doi:10.1177/1464884911412707

Holliman, R., Adams, A., Blackman, T., Collins, T., Davies, G., Dibb, S., et al. eds. (2015). An Open Research University. Milton Keynes: The Open University.

Jenkins, H., Purushotma, R., Weigel, M., Clinton, K., and Robison, A. (2009). Confronting the Changes of Participatory Culture: Media Education for the $21^{\text {st }}$ Century. Massachusetts: MIT Press.

Katz, R. (2010). Scholars, scholarship and the digital age. Educause Review 45: 44-56.

Klein, J.T. (1990). Interdisciplinarity: History, Theory, and Practice. Detroit, MI: Wayne State Press.

Klein, J.T. (2010). Creating Interdisciplinary Campus Cultures: A Model of Strength and Sustainability. San Francisco: Jossey-Bass.

Lane, A., and McAndrew, P. (2010). Are open educational resources systematic or systemic change agents for teaching practice? Br. J. Educ. Technol. 41, 952-962. doi:10.1111/j.1467-8535.2010.01119.x

Moran, J. (2010). Interdisciplinarity. New York: Routledge.

Pearce, N., Weller, M., Scanlon, E., and Kinsley, S. (2010). Digital Scholarship Considered: How New Technologies Could Transform Academic Work. In Education 16,1. Available at: http://oro.open.ac.uk/24699

Scanlon, E. (2011). Digital futures: changes in scholarship, open educational resources and the inevitability of interdisciplinarity. Arts and Humanities in Higher Education 11: 177-84. doi:10.1177/1474022211429279

Scanlon, E. (2013). Scholarship in the digital age: open educational resources, publication and public engagement. British Journal of Educational Technology 45: 12-23. doi:10.1111/bjet.12010

Scanlon, E., McAndrew, P., and O’Shea, T. (2016). Citizen science and learning: formal, informal or at scale? In First European Citizen Science Association, Berlin.

Scanlon, E., and Taylor, J. (2016). Is technology enhanced learning an interdisciplinary activity? In Proceedings of the Networked Learning Conference, Lancaster.

Schmiede, R. (2009). Upgrading academic scholarship: challenges and chances of the digital age. Library Hi Tech 27: 624-33. doi:10.1108/07378830911007727

Singh, S. (2016). Open Wounds the Myth of Open as a Panacea. Available at: https://oer16. oerconf.org/sessions/open-wounds-the-myth-of-open-as-a-panacea-1167/ 
Strober, M. (2011). Interdisciplinary Conversations: Challenging Habits of Thought. California: Stanford University Press.

Turner, A. (2000). What are disciplines and how is interdisciplinarity different? In Practicing Interdisciplinarity, Edited by Wong Peter and Nico Steve. Toronto: Toronto University Press.

Veletsianos, G., and Kimmons, R. (2012). Networked participatory scholarship: emergent techno-cultural pressures toward open and digital scholarship in online networks. Computers and Education 58: 766-74. doi:10.1016/j.compedu.2011.10.001

Weller, M. (2011). The Digital Scholar, How Technology Is Transforming Scholarly Practice. London: Bloomsbury Press.

Weller, M. (2014). The Battle for Open, How Openness Won and It Doesn't Feel Like a Victory. London: Ubiquity Press.

Wilinsky, J., and Alperin, J.P. (2011). The academic ethics of access to research and scholarship. Ethics and Education 6, 217-23.
Yankelovich, H. (1999). The Magic of Dialogue Transforming Dialogue into Cooperation. New York: Simon and Schuster.

Conflict of Interest Statement: The author declares that the research was conducted in the absence of any commercial or financial relationships that could be construed as a potential conflict of interest.

Copyright (c) 2018 Scanlon. This is an open-access article distributed under the terms of the Creative Commons Attribution License (CC BY). The use, distribution or reproduction in other forums is permitted, provided the original author(s) and the copyright owner are credited and that the original publication in this journal is cited, in accordance with accepted academic practice. No use, distribution or reproduction is permitted which does not comply with these terms. 